\title{
SELFIE DAS ESTRUTURAS: UMA METODOLOGIA DE ENSINO COM USO DA FOTOGRAFIA
}

\author{
SELFIE OF STRUCTURES: USE OF PHOTOGRAPHY AS A TEACHING \\ METHODOLOGY
}

Simone Rodrigues Campos Ruas ${ }^{1}$, Nayabe Bernardes de Araujo ${ }^{2}$

DOI: 10.37702/REE2236-0158.v40p209-218.2021

\begin{abstract}
RESUMO
Discussões sobre os desafios do ensino na sociedade atual e seu aperfeiçoamento têm ganhado espaço em âmbito acadêmico, principalmente diante de um contexto marcado por constantes evoluções tecnológicas e pelo dinamismo das relações interpessoais, no qual a fotografia se faz presente de forma expressiva. Somando-se a isso a coexistência de diferentes alunos, com processos cognitivos diversos, em sala de aula, torna-se importante idealizar estratégias que contemplem os vários mecanismos de aprendizagem. Desse modo, o presente artigo estuda a aplicação da fotografia como uma alternativa de metodologia didática aplicada em turmas da disciplina de Teoria das Estruturas 1, constante na grade curricular do curso de Engenharia Civil da Universidade Federal de Viçosa-Campus Rio Paranaíba. A disciplina introduz os discentes na área da engenharia estrutural e seu estudo engloba a identificação de diferentes tipos de elementos estruturais, bem como os esforços e deslocamentos a que possam estar submetidos. A proposta deste estudo foi baseada na correlação do que foi estudado em sala de aula com a identificação de estruturas que fizessem parte do cotidiano dos alunos, por meio da fotografia. A metodologia propôs que os alunos fotografassem as estruturas estudadas durante o semestre letivo, apresentando-as posteriormente na sala de aula. A análise da eficiência da metodologia empregada foi realizada através de um questionário de caráter qualitativo em que os discentes puderam repassar suas percepções acerca da proposta. O levantamento estatístico das respostas obtidas no questionário evidenciou a eficácia da metodologia, contribuindo para a absorção do conteúdo, interação entre os alunos, engajamento na disciplina e apuramento das competências perceptivas e críticas.
\end{abstract}

Palavras-chave: metodologia ativa de ensino; fotografia; Engenharia.

\begin{abstract}
Discussions about the challenges of teaching, and its possible improvement, in our current society have been gaining space in the academic sphere, especially in the context of constant technological developments and the dynamism of interpersonal relationships in which photography is present in an expressive way. To add to this, the coexistence of different students, with diverse cognitive processes, in the classroom, makes it important to develop strategies that include diverse learning mechanisms. As such, this article examines the application of photography as an altenative of didatic methodology, as
\end{abstract}

\footnotetext{
${ }^{1}$ Profa. Me. Adjunta, Instituto de Ciências Exatas e Tecnológicas, Universidade Federal de Viçosa - Campus Rio Paranaíba, simone.ruas@ufv.br

${ }^{2}$ Discente, Universidade Federal de Viçosa - Campus Rio Paranaíba, nayabe.araujo@ufv.br
} 
applied in classes of the discipline "Structural Theory 1", included in the curriculum of the Civil Engineering course at the Federal University of Viçosa - Campus Rio Paranaíba. The discipline introduces students to the field of structural engineering, and its study includes the identification of different types of structural elements, as well as the forces and displacements to which they may be subjected. This study proposition was based on the correlation between what was studied in the classroom and the identification of structures that were part of the students' daily lives through photography. The methodology proposed that students photographed the structures studied during the school semester and presented them later in the classroom. An analysis of the efficiency of the employed methodology was carried out through a qualitative questionnaire in which the students were able to reveal their perceptions about the proposal. The statistical survey of the answers obtained in the questionnaire provided evidence that the methodology was effective, contributed to content comprehension, promoted interaction between students, increased engagement with the discipline and sharpened perceptual and critical skills.

Keywords: active teaching metodologhy; photography; Engineering.

\section{INTRODUÇÃO}

Ao optar por uma metodologia didática, o professor escolhe um caminho que o auxilie no objetivo de alcance da aprendizagem. Para isso, considera-se o emprego de raciocínios como a correlação, observação, distinção, conclusão e dedução na formação do conhecimento. Também, a escolha dos métodos e técnicas de ensino é baseada no aluno e suas características intelectuais; no conteúdo, sua natureza e lógica; no contexto e nas circunstâncias que envolvem o aprendiz, o professor, a instituição de ensino e a comunidade (RANGEL, 2007).

Focalizando o Ensino de Engenharia na sociedade atual, comumente se encontra um modelo engessado de reprodução do conhecimento. Segundo Belhot, Figueiredo e Malavé (2001), o padrão de ensino adotado se baseia numa propagação de conhecimento voltada aos conceitos e teorias, com estímulo à memorização em detrimento da contextualização. A partir dessa lógica, a repetição de mecanismos conceituais e aplicação de métodos que buscam exclusivamente a resolução do problema passam a se sobressair.

Borba e Costa (2010) ressaltam as incongruências dos métodos de aprendizagem enfatizando o descompasso entre a evolução tecnológica vivida e as técnicas de ensino norteadas na simples transmissão do conteúdo. Nesse ínterim, os autores evidenciam a necessidade de um modelo revolucionário, que torne o futuro profissional apto a enfrentar os desafios do novo cenário.

Dentro dessa revolução tecnológica vivida, pode-se destacar o uso da fotografia, que nos dias atuais se tornou muito popular diante da facilidade de sua captura. A popularização do smartphone é crescente, assim todos têm uma forma de se expressar pela fotografia. A formação da imagem hoje é instantânea e ao mesmo tempo pode ser vista por várias pessoas em um curto intervalo de tempo. É um recurso muito utilizado entre todos, principalmente entre os jovens. Dessa forma, a fotografia, como ferramenta adicional na sala de aula para contextualizar conteúdos, está sendo utilizada em várias áreas do conhecimento, por exemplo: no ensino da Química Analítica (LIMA; CUNHA, 2019), da Sociologia (BODART, 2015), da Geografia (SILVA, 2013) entre outros.

Com base nessas ideias, o presente trabalho é apresentado como forma de análise de uma metodologia alternativa de ensino, utilizando a fotografia, aplicada na disciplina Teoria das Estruturas 1, oferecida no $6^{\circ}$ período do curso de Engenharia Civil da Universidade Federal de Viçosa - Campus Rio Paranaíba. Tal metodologia é baseada em processos de 
associação e comparação, em que as estruturas estudadas em sala de aula durante o andamento da disciplina devem ser identificadas e fotografadas pelos alunos em seu cotidiano para que, posteriormente, a imagem seja apresentada aos colegas e professor. A eficácia desta proposta foi avaliada por meio de um questionário respondido pelos alunos ao final da disciplina.

\section{FUNDAMENTAÇÃO TEÓRICA}

Tem sido crescente a busca de professores e profissionais da área de Ensino de Engenharia por melhorias em suas estratégias didáticas, uma vez que um direcionamento estratégicopedagógico auxilia no processo de ensinoaprendizagem. Bernardinis et al. (2017) apontam que "a inclusão de ferramentas que tornem a aula mais dinâmica e que contemplem os diferentes tipos de aprendizado se faz necessária no contexto atual da educação como solução para o ensino na engenharia, no sentido em que possam motivar mais os alunos" (BERNARDINIS, 2017, p. 111).

Segundo Pereira (2005, p. 2) "o engenheiro precisa de um sólido conhecimento dos princípios fundamentais da Engenharia Civil, do domínio de aprimoradas estratégias de solução de problemas e de capacidade para pensar e agir de forma independente". Dessa forma, é natural se pensar na importância do método de ensino adotado, bem como nas consequências surtidas quando aplicado de maneira correta, com a finalidade de levar à compreensão de um conteúdo.

Diferentes alternativas pedagógicas podem ser exploradas visando à simplificação do mecanismo requerido ao entendimento e facilitação do processo de correlação com as situações reais a serem enfrentadas no ambiente de trabalho. Pensando nas incumbências do engenheiro estrutural, Rocha et al. (2017) ressaltam a importância de que esse profissional tenha a capacidade de distinguir a conduta das estruturas em meio a diferentes situações, tendo em vista que, por visar normalmente aos parâmetros estéticos e econômicos, a idealização do projeto estrutural e as decisões iniciais apresentam valores qualitativos e intuitivos.

Silva (2017) conclui que o processo de educar hoje apresenta o desafio de incorporar novas estratégias didáticas pedagógicas em harmonia com as alterações no perfil dos discentes e a presença das novas tecnologias em sala de aula. Dentro dessas novas tecnologias está o uso constante da fotografia, já que o interesse pelo visual tem crescido no decorrer dos anos, tornando-se uma nova forma de expressão e fonte de estudos para diversos pesquisadores.

Diante dessa mudança de comportamento frente à fotografia, estudos têm sido feitos para avaliar as possibilidades desta como ferramenta de ensino. Quando trabalhada de forma conjunta à aprendizagem, a fotografia revela elevado potencial didático-pedagógico, atuando não só através da faceta integradora entre a teoria vista em aula e a prática, mas também proporcionando a estruturação de um olhar atento e crítico ao meio exposto. A interação com o ambiente fotografado promove o desenvolvimento sequenciado da observação, da indagação, da análise e da crítica, sendo assim um instrumento auxiliador na percepção e construção do conhecimento (MOURA; SANTANA, 2013).

Como exemplo, cita-se Bodart (2015), que estudou as potencialidades do uso da fotografia como recurso didático no ensino da Sociologia. Nesse estudo, o autor concluiu que o uso da fotografia deve ser acompanhado de uma base teórica para poder haver uma correlação eficiente do "ver", do "compreender" através da imagem. Além disso, analisando-a, quando inserida no contexto do ensino, o autor afirma que "pensar o uso de recursos didáticos, como a fotografia, sob um arcabouço teóricometodológico norteador é cada vez mais urgente" (BODART, 2015, p. 99).

$\mathrm{Na}$ área de Exatas, os autores Maciel, Rêgo e Carlos (2017) avaliaram as possibilidades pedagógicas do uso da imagem fotográfica no livro de Matemática. Esse trabalho concluiu que as fotografias podem exercer as funções ilustrativa, comunicativa, decorativa e de transmissão de conhecimento em relação aos diversos conteúdos de Matemática, 
especificamente em Geometria, em particular no de simetria.

Por sua vez, Lima e Cunha (2019) avaliaram a fotografia como recurso didático para integrar conceitos de Química Analítica. Os estudantes do curso de graduação em Química foram motivados a fotografar os fenômenos que envolvem o equilíbrio químico no seu dia a dia. A conclusão desse estudo foi que os alunos se concentraram em trazer exemplos de fotografias já presentes nos livros; ou seja, não se "aventuraram" em trazer para a sala de aula novas situações. Porém, segundo os autores, $\mathrm{o}$ ato de fotografar mostrou-se motivador para os estudantes, contribuindo para a melhoria da compreensão da disciplina.

\section{METODOLOGIA}

A disciplina Teoria das Estruturas 1 faz parte da grade de matérias obrigatórias de um curso de Engenharia Civil. É uma disciplina muito importante justamente por iniciar os alunos na engenharia estrutural, em que a compreensão do funcionamento de uma estrutura irá nortear toda a concepção de um projeto. No final dessa disciplina o aluno deve ter condições de identificar os diversos tipos de elementos estruturais existentes e os esforços e deslocamentos a que estão submetidos. Para alcançar tal objetivo, é necessário que haja uma abstração dos discentes, já que o conteúdo ministrado requer concentração para compreensão.

O curso de Engenharia Civil da Universidade Federal de Viçosa - Campus Rio Paranaíba tem entrada anual de 50 alunos e se estrutura em regime semestral. A disciplina Teoria das Estruturas 1 é oferecida no $6^{\circ}$ período e possui uma carga horária de 5 horas/aula semanais. A metodologia estudada foi aplicada em dois períodos, $2^{\circ}$ semestre de 2018 e $2^{\circ}$ semestre de 2019. Nesses dois períodos a disciplina contou com um total de 76 alunos matriculados.

Para que os alunos compreendessem a aplicabilidade do que estava sendo apresentado em sala de aula, foi solicitado que fotografassem estruturas reais que contivessem os elementos estruturais estudados. Desse modo, por meio da associação com o que é visto em uso no cotidiano, os estudantes teriam outra forma de assimilar o conteúdo apresentado em sala de aula.

A apresentação das fotos por parte dos alunos seguiu algumas regras, as quais foram: a foto teria que conter o estudante, para que não houvesse possibilidade de o registro não ser de sua autoria; de acordo com o andamento da disciplina, teriam dois momentos para que essas fotos fossem apresentadas e para cada momento deveria ser fotografada uma estrutura diferente; a apresentação das fotos garantia pontos ao final da disciplina de Teoria da Estruturas 1.

Para o primeiro momento de apresentação das fotos, os alunos puderam escolher entre estruturas nas quais fosse possível identificar os apoios (de $1^{\circ}, 2^{\circ}$ e $3^{\circ}$ gêneros), e/ou os diversos tipos de vigas existentes (viga engastada e livre, biapoiada, etc). No segundo momento de apresentação das fotos, as estruturas deveriam ser pórticos, treliças, grelhas ou arcos. Nesse segundo momento de apresentação das fotos, os alunos deveriam fazer um esboço, na própria foto, da representação do carregamento e de como seria o modelo estrutural que representaria a referida estrutura.

A apresentação das fotos ocorreu no horário de aula. No momento da apresentação, todas as fotos entregues foram agrupadas em um arquivo digital e apresentadas em datashow para que todos vissem. Alguns alunos foram sorteados para comentar a respeito da foto que enviaram.

Para a divulgação das fotos neste trabalho, foi solicitada aos alunos a assinatura de um termo de autorização de uso da imagem.

\section{Questionário}

Ao fim de cada semestre (após a aplicação da última avaliação) foi solicitado aos discentes da disciplina Teoria das Estruturas 1 que respondessem um questionário envolvendo perguntas relacionadas à proposta do uso das fotos das estruturas como alternativa didática. Nesse questionário não havia forma de identificação do aluno.

Buscando a facilitação do processo de apuramento das respostas, o questionário foi 
baseado predominantemente na escala Likert, sendo que foram feitas também perguntas abertas. $\mathrm{O}$ uso dessa escala funcionou como um tratamento estatístico para a validação dos dados. O desenvolvimento do questionário foi realizado de forma que as respostas fornecessem um feedback qualitativo acerca das estratégias em análise. Vale ressaltar que, apesar de incentivada, a participação na proposta foi facultativa, tendo sido adotada uma pergunta no questionário que levantasse a quantidade de alunos não participantes e o motivo da não participação.

A fim de facilitar a apuração estatística de perguntas fechadas em congruência com a escala Likert, foram atribuídos números a cada possível resposta, sendo 1 para a opção "discordo totalmente", 2 para "discordo parcialmente", 3 para "concordo parcialmente" e 4 para "concordo totalmente". Os cálculos necessários para a validação estatística foram realizados por meio do software livre "R", sendo que esta ocorre pela igualdade entre os valores de moda e mediana encontrados para o conjunto amostral.

O questionário apresentou oito perguntas, das quais a primeira (fechada) questionava se o aluno aderiu à proposta $\mathrm{e}$, caso a resposta fosse "não", solicitava-se que respondesse a segunda (aberta) informando o motivo da não participação. Se a resposta do discente na primeira pergunta fosse "sim", ele era direcionado às perguntas $3,4,5,6$ e 7, baseadas na escala likert (fechadas).

A pergunta 3 avaliou se a participação na metodologia de ensino estimulou o aluno a desenvolver uma visão diferenciada para as construções e elementos estruturais a ela associados, como pilares e vigas. Já a pergunta 4 questionou se, no ato de buscar as estruturas para o registro fotográfico, foi possível ter uma melhor compreensão sobre elas e sobre a forma de atuação dos esforços. De forma similar, a pergunta 7 avaliou se houve uma melhor compreensão sobre como as estruturas estudadas são empregadas em obras de engenharia civil.

A pergunta 5 indagou se, buscando estruturas reais estudadas em sala de aula para a realização das fotos, houve uma maior compreensão da disciplina de Teoria das Estruturas 1. Tendo em vista que foram destinados alguns pontos para os participantes da proposta, a pergunta 6 avaliou se a existência desses pontos foi relevante para a adesão do aluno. Por fim, a pergunta 8 (aberta) solicitou que o aluno fizesse algum comentário a respeito de sua experiência mediante a introdução da metodologia didática no curso.

\section{RESULTADOS}

No $2^{\circ}$ semestre de 2018 , dentre os 33 alunos matriculados na disciplina de Teoria das Estruturas I, 29 responderam o questionário, configurando um total de $87,9 \%$ da turma analisada quanto aos métodos empregados. Entretanto, dentre os 29 respondentes, somente 26 alegam ter participado da proposta. Desse modo, para fins de constatação estatística do método avaliado, somente esses 26 alunos serão considerados no conjunto de dados adotados para a validação pela escala Likert.

Já no $2^{\circ}$ semestre de 2019 , dentre os 43 alunos matriculados, 34 responderam ao questionário (79,1\% da turma), sendo que todos os respondentes participaram da proposta. Assim, temos um total de 76 alunos matriculados nos dois semestres e 63 alunos que responderam ao questionário, sendo 60 participantes da proposta.

\section{Fotos das estruturas}

Em relação à proposta de fotografar as estruturas encontradas, dentre a população analisada por meio do questionário, houve uma participação de $95,2 \%$, sendo que os outros $4,8 \%$ justificaram a não participação por não gostarem de fazer apresentações orais, atividade requerida na aplicação da metodologia. Vale ressaltar que, ao não participarem, esses alunos se abstiveram da nota referente à atividade.

Durante o decorrer do semestre, as datas das apresentações foram marcadas de acordo com o andamento das matérias e com as datas das avaliações. A Figura 1 e Figura 2 mostram exemplos das fotos apresentadas sobre o 
conteúdo da primeira prova; ou seja, vigas e pórticos. Já a Figura 3, a Figura 4 e a Figura 5 exemplificam a situação de fotos referentes às matérias da segunda e terceira provas (treliças, arcos e grelhas).

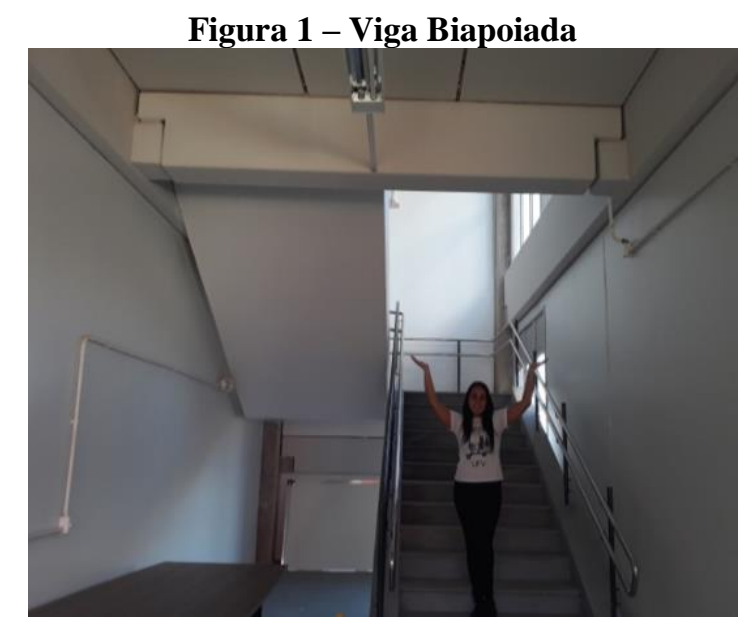

Fonte: Sara Reis.

Figura 2 - Pórtico engastado e livre

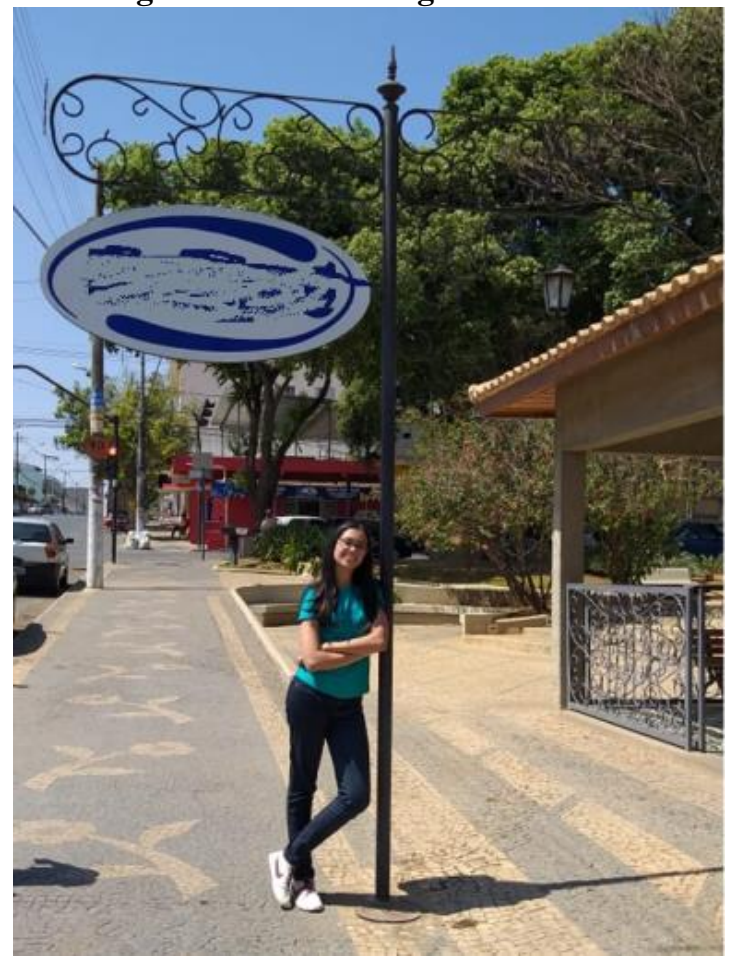

Fonte: Gabrielle Dias.

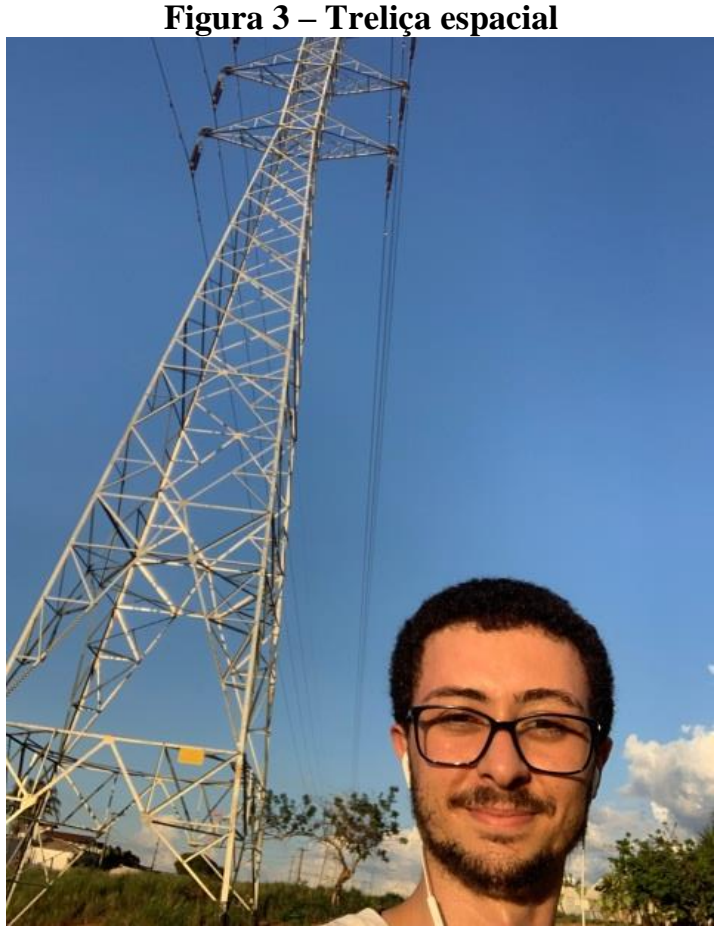

Fonte: Igor Luz

Figura 4 - Arcos

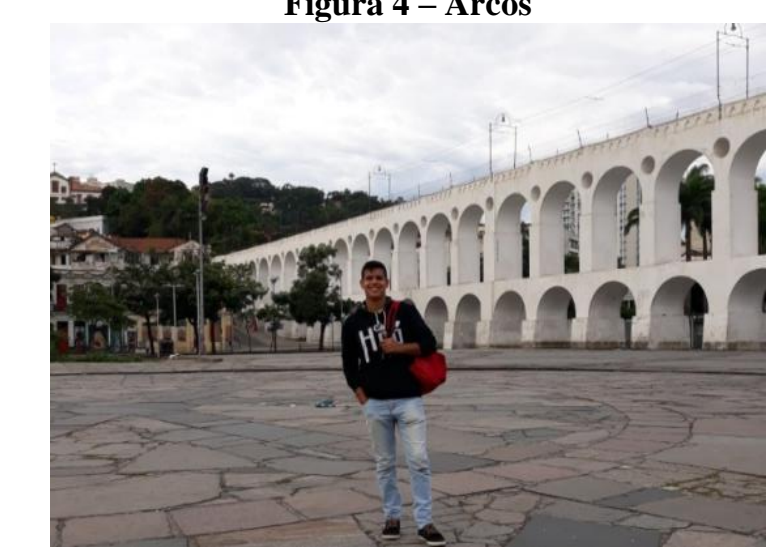

Fonte: Hecton de Sousa.

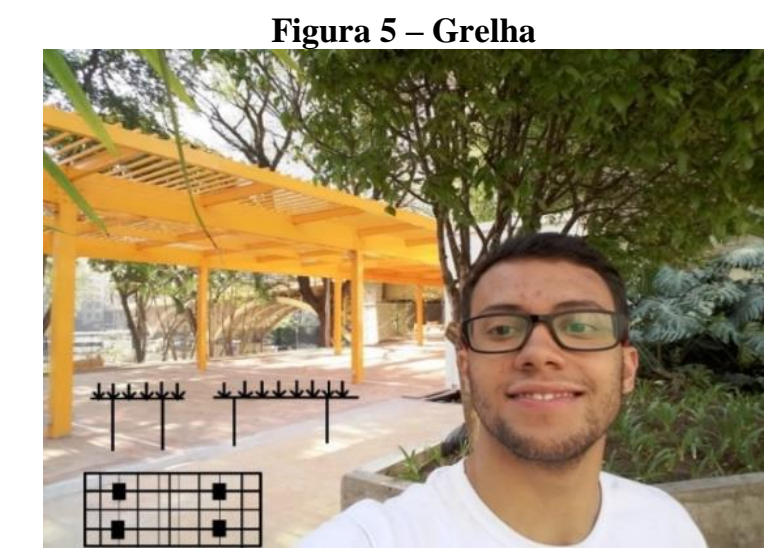

Fonte: Tiago Nogueira. 
A motivação dos estudantes em fotografar estruturas que se enquadravam no que havia sido estudado foi notória. A variedade de situações em que as fotos foram criadas se mostrou ampla. A foto a seguir (Figura 6) é um exemplo dessa situação. A aluna tirou a fotografia em um momento de uma festa da qual ela participava, ou seja, a correlação entre o que se estudou e a vida "real" foi perfeitamente estabelecida.

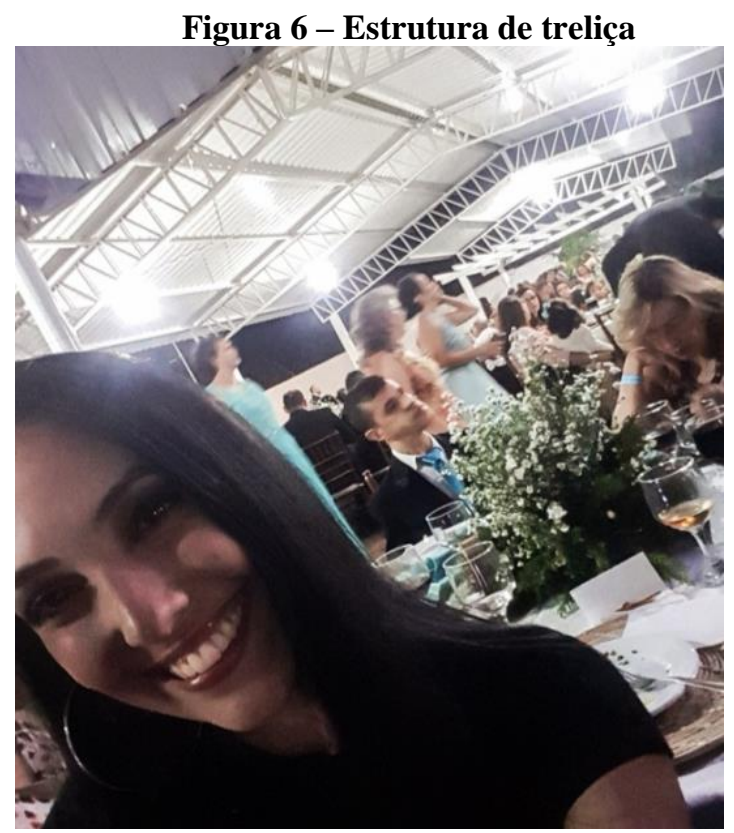

Fonte: Gabriela Costa.
Para o estudo, considerou-se uma amostra da população relativa aos 60 alunos participantes da proposta. As relações percentuais entre as respostas obtidas nos questionários e a frequência das respostas juntamente com os valores de moda e mediana estão dispostos, respectivamente, na Tabela $1 \mathrm{e}$ na Tabela 2.

A análise das respostas obtidas evidenciou que a população concorda totalmente que a proposta levou a uma melhor compreensão do funcionamento das estruturas e da forma como os esforços atuam sobre estas (pergunta 4), sendo benéfica para o entendimento geral da disciplina de Teoria das Estruturas I (pergunta 5).

Também houve uma concordância total de que a busca pelas estruturas a serem fotografadas auxiliou na percepção de como estas são empregadas em obras da engenharia civil (pergunta 7) e estimulou um melhor apuramento crítico das construções e elementos estruturais estudados (pergunta 3), atributo este necessário às atividades do engenheiro civil.

Questionados sobre a motivação para a participação da proposta, grande parte dos alunos $(48,3 \%)$ concordou que o fato de serem destinados pontos à atividade foi um fator relevante (pergunta 6).

Tabela 1 - Porcentagens das respostas obtidas

\begin{tabular}{ccccc}
\hline Pergunta & Disc. Tot. (1) & Disc. Par. (2) & Conc. Par. (3) & Conc. Tot. (4) \\
\hline 3 & 0 & 0 & $20 \%$ & $80 \%$ \\
4 & 0 & 0 & $25 \%$ & $75 \%$ \\
5 & 0 & $3,3 \%$ & $30 \%$ & $66,7 \%$ \\
6 & $3,3 \%$ & $8,3 \%$ & $40 \%$ & $48,3 \%$ \\
7 & 0 & 0 & $10 \%$ & $90 \%$ \\
\hline
\end{tabular}

Fonte: elaborada pelas autoras.

Tabela 2 - Frequência das respostas e validação

\begin{tabular}{ccccccc}
\hline Pergunta & Disc. Tot. (1) & Disc. Par. (2) & Conc. Par. (3) & Conc. Tot. (4) & Mediana & Moda \\
\hline 3 & 0 & 0 & 12 & 48 & 4 & 4 \\
4 & 0 & 0 & 15 & 45 & 4 & 4 \\
5 & 0 & 2 & 18 & 40 & 4 & 4 \\
6 & 2 & 5 & 24 & 29 & 3 & 4 \\
7 & 0 & 0 & 6 & 54 & 4 & 4 \\
\hline
\end{tabular}

Fonte: elaborada pelas autoras. 
Ao final do questionário foi disponibilizado um espaço para que o aluno pudesse deixar algum comentário sobre a experiência de ter cursado a disciplina de Teoria das Estruturas $1 \mathrm{com}$ a associação da proposta das fotografias. Nessa questão tiveram alguns depoimentos relevantes:

\begin{abstract}
"Acredito que seja um método muito relevante, pois tive que ter um olhar crítico ao meu redor para conseguir as fotos e com isso tive dúvidas o que me ajudou a entender o conteúdo"

"Foi muito bom, pois ilustra o que víamos em aula, em nosso cotidiano, trazendo assim maior curiosidade e raciocínio"

"O fato de buscar pelas fotos, gerou uma discussão válida entre os colegas, tentando chegar a uma conclusão se a estrutura escolhida era ou não um pórtico, ou treliça ou outra estrutura."
\end{abstract}

\section{CONSIDERAÇÕES FINAIS}

Para um engenheiro civil, compreender como uma estrutura "trabalha" é de suma importância. A disciplina de Teoria das Estruturas 1 faz parte da iniciação do discente no processo de compreensão do comportamento estrutural. Assim, a forma como esse processo de aprendizagem se inicia tem importância fundamental no desenvolvimento profissional do futuro engenheiro.

Este trabalho mostrou que a inserção da atividade de fotografar estruturas foi muito bem aceita pelos alunos e que houve motivação para desenvolvê-lo. No entanto, parte dos estudantes disseram que a motivação para apresentar a fotografia estava relacionada ao fato de serem destinados pontos à atividade. Pode-se dizer que esse cenário faz parte da resistência inicial do aluno às metodologias novas de ensino, já que o modelo tradicional está mais arraigado a sua existência, conforme concluíram Lima e Cunha (2019).

Neste trabalho, a disciplina de Teoria das Estruturas tem grande parte de seu conteúdo transmitido aos seus alunos pelo modelo tradicional de ensino, em que o professor apresenta a parte teórica do assunto. Tal conhecimento prévio e teórico é muito importante para que o aluno possa identificar as estruturas em seu cotidiano, conforme já concluído por Bodart (2015).

$\mathrm{O}$ ato de fotografar fez do aluno um agente ativo da situação, criou uma inquietude no sentido de encontrar na vida "real" a estrutura que estava sendo estudada e isso gerou motivação, comprovada pelos depoimentos. A apresentação das fotos para os colegas ampliou a conexão da turma com o assunto estudado e suscitou momentos de descontração que facilitaram a absorção de conhecimentos.

A fotografia, em si, é uma forma de olhar mais atenta para a paisagem e neste trabalho não foi diferente. Fazer a conexão com o que foi ensinado em sala de aula, através do processo de fotografar, facilitou $\mathrm{o}$ ato de correlacionar com as situações reais a serem enfrentadas no ambiente de trabalho de um engenheiro. Assim, conclui-se que para a disciplina de Teoria da Estruturas 1, a utilização de fotografias como uma metodologia ativa de ensino foi de extrema importância para o sucesso da disciplina, sendo um procedimento a ser seguido para os próximos semestres como complemento à apresentação teórica dos conceitos.

\section{REFERÊNCIAS}

BELHOT, R. V.; FIGUEIREDO, R. S.; MALAVÉ, C. O Uso da Simulação no Ensino de Engenharia. Anais... XXIX Congresso Brasileiro de Ensino de Engenharia. Porto Alegre, 2001.

BERNARDINIS, M. A. P. et al. Grupo de estudos como alternativa inovadora para o aprimoramento no processo de ensino no curso de Engenharia Civil da Universidade Federal do Paraná. Revista Principia, João Pessoa, n. 34, 2017.

BORBA, J. L.; COSTA, L. A aprendizagem na engenharia. Revista conhecimento online, Novo Hamburgo, 2010.

BODART, C. N. Fotografia como recurso didático no ensino de sociologia. Em Tese, Revista do 
PPGSP da UFSC, Brasil, v. 12, n. 2, ISSNe 1806-5023, ago./dez., 2015.

CUNHA, M. B. et al. Uma metodologia para avaliar as percepções de Ciência e Tecnologia dos estudantes. Anais... VII ENPEC ENCONTRO NACIONAL DE PESQUISA EM EDUCAÇÃO E CIÊNCIAS, Campinas, 2011.

FERREIRA, M. G. P. et al. Metodologias ativas de aprendizagem aplicadas no ensino da engenharia. Anais... CONGRESSO INTERNACIONAL DE EDUCAÇÃO E TECNOLOGIAS, 2018, São Carlos, [s. n.], 2018.

KURI, N. P. Tipos de personalidade e estilos de aprendizagem: proposições para o ensino de engenharia. 2004. Tese (Doutorado em Engenharia de Produção) - Universidade Federal de São Carlos, São Carlos, 2004.

LLAURADÓ, O. Escala de Likert: o que é e como utilizá-la. [S. l.], 23 jan. 2015. Disponível em: https://www.netquest.com/blog/br/escalalikert. Acesso em: 15 jan. 2019.

LIMA, F. O.; CUNHA, M. B. A fotografia como recurso didático para contextualizar conceitos de Química Analítica. Research, Society and Development, v. 9, n. 3, ISSN 2525-3409. 18dez., 2019.

MACIEL, A. M.; RÊGO, R. G.; CARLOS, E. J. Possibilidades pedagógicas do uso da imagem fotográfica no livro didático de Matemática. Bolema, v. 31, n. 57, Rio Claro. ISSN 19804415. jan./abr. 2017.

MOURA, J. D. P.; SANTANA, D. A. A reeducação do olhar por meio de fotografias socioambientais. IV Encontro Nacional de Estudos de Imagem, Londrina, p. 1505-1512, 2013.

PEREIRA, M. A. Ensino-aprendizagem em um contexto dinâmico - $O$ caso de planejamento de transportes. 2005. Tese (Doutorado em Engenharia Civil) - Universidade de São Paulo, São Carlos, 2005.

PONCIANO, T. M.; GOMES, F. C. V.; MORAIS, I. C. Metodologia ativa na engenharia: verificação da ABP em uma disciplina de Engenharia de Produção e um modelo passo a passo. Revista Principia, João Pessoas, n. 34, 2017.

RANGEL, M. Métodos de ensino para a aprendizagem e dinamização das aulas. 3.ed. Campinas: Papirus, 2007.

ROCHA, A. C. C. et al. Análise do comportamento estrutural através de simulações de protótipos: para fins didáticos. Anais... XLV CONGRESSO BRASILEIRO DE EDUCAÇÃO EM ENGENHARIACOBENGE, 2017, Joinville. Joinville: Abenge, 2017.

\section{DADOS BIOGRÁFICOS DOS AUTORES}

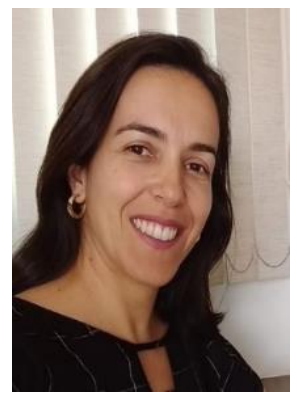

Simone Rodrigues Campos Ruas - Possui graduação em Engenharia Civil pela Universidade Federal de Viçosa, em 2000; especialização em Segurança do Trabalho, pela Universidade Federal do Rio de Janeiro, em 2006; especialização em Engenharia de Campo - Construção e Montagem, pela Universidade Federal Fluminense, em 2007; e mestrado em Construções Metálicas, pela Universidade Federal de Ouro Preto, em 2003. Trabalhou na área de infraestrutura aeroportuária no Departamento de Aviação Civil e na Agência Nacional de Aviação Civil. Atualmente é professora na Universidade Federal de Viçosa - Campus Rio Paranaíba, atuando nas áreas de resistência dos materiais, teoria das estruturas, segurança do trabalho e infraestrutura aeroportuária. 


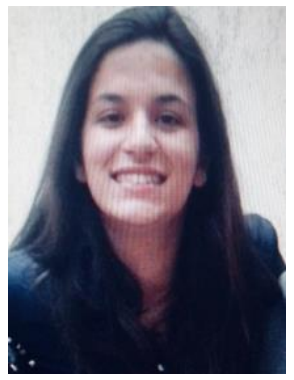

Nayabe Bernardes de Araujo - Discente do curso de Engenharia Civil pela Universidade Federal de Viçosa - Campus Rio Paranaíba. 